\title{
Multiple Fetal Nutritional Patterns Before Parturition in Viviparous Fish Sebastes schlegelii (Hilgendorf, 1880)
}

\section{OPEN ACCESS}

Edited by:

Antonio Trincone,

Consiglio Nazionale delle Ricerche

(CNR), Italy

Reviewed by:

Angela Cuttitta,

National Research Council (CNR), Italy

Mari Carmen Uribe,

National Autonomous University of

Mexico, Mexico

${ }^{*}$ Correspondence:

Li Jun

junli@qdio.ac.cn

†These authors share co-first authorship

Specialty section:

This article was submitted to

Marine Biotechnology,

a section of the journal

Frontiers in Marine Science

Received: 12 June 2020 Accepted: 15 December 2020 Published: 14 January 2021

Citation:

Tengfei $D$, Yongshuang $X$, Haixia Z, Li Z, Qinghua L, Xueying W, Jun L, Shihong $X$, Yanfeng $W$, Jiachen $Y$, Lele W, Yunong $W$ and Guang $G$

(2021) Multiple Fetal Nutritional

Patterns Before Parturition in

Viviparous Fish Sebastes schlegeli (Hilgendorf, 1880).

Front. Mar. Sci. 7:571946. doi: 10.3389/fmars.2020.571946

\begin{abstract}
Du Tengfei ${ }^{1,2,3 \dagger}$, Xiao Yongshuang ${ }^{1,2,4 t}$, Zhao Haixia ${ }^{1,2,3}$, Zhou Li ${ }^{1,2,3}$, Liu Qinghua ${ }^{1,2}$, Wang Xueying ${ }^{1,2}$, Li Jun ${ }^{1,2,4 *}$, Xu Shihong ${ }^{1,2}$, Wang Yanfeng ${ }^{1,2}$, Yu Jiachen ${ }^{1,2,3}$, Wu Lele Le,2,3 $^{1,}$ Wang Yunong ${ }^{1,2,3}$ and Gao Guang ${ }^{1,2,3}$

${ }^{1}$ The Key Laboratory of Experimental Marine Biology, Centre for Ocean Mega-Science, Institute of Oceanology, Chinese Academy of Sciences, Qingdao, China, ${ }^{2}$ Laboratory for Marine Biology and Biotechnology, Qingdao National Laboratory for Marine Science and Technology, Qingdao, China, ${ }^{3}$ University of Chinese Academy of Sciences, Beijing, China, ${ }^{4}$ Southern Marine Science and Engineering Guangdong Laboratory (Guangzhou), Guangzhou, China
\end{abstract}

Sebastes schlegelii is a commercially important fish with a special viviparous reproductive system that is cultured in near-shore seawater net cages in East Asia. In the gonadal development of the species, the gonad of males mature before those of females, which mature after mating. Mating in male/female fishes occurs in October of each year. Then, females undergoing oocyte maturation complete fertilization using stored sperm in March of the following year. The pregnancy is completed when larvae are produced in the ovary. It has been reported that embryonic nutrient supply originates entirely from the female viviparous reproductive systems. However, until now, the nutritional patterns and the processes of nutrient provision in S. schlegelii before parturition have not been clear. The goal of this research was to study the embryos, larvae and juveniles of $S$. schlegelii during pregnancy. Anatomical observations, light microscopy and scanning electron microscopy were used to study the developmental characteristics of early embryos and larvae and the connecting structures between the mother and the fetus. The results showed the following: (1) Placental-like structures were found during the process of embryonic development in S. schlegelii, and these placental-like structures proliferated after fertilization. (2) The embryos of $S$. schlegelii were encased by a saclike structure composed of blood vessels, connective tissue, and surface epithelial cells. The vessels near the embryo existed in the thecal layer. Vascularized proliferation was detected following embryonic development. (3) Starting in the gastrula stage, connections between the embryo and surrounding cells loosened, and ovarian fluid became abundant. In addition, a large number of small holes and cristae were observed on the surface of the embryo. We speculate that embryos may be able to absorb nutrients from the ovarian fluid. (4) Yolk was present throughout embryo development. (5) Two types of nutritional modes were observed, lecithotrophic and matrotrophic during embryonic development. Three forms of placental analogs may exist in S. schlegelii: (1) external epithelial absorptive surfaces; (2) trophonemata, with modifications of the ovarian epithelia for absorbing the histotroph; and (3) a follicular pseudoplacenta, with close apposition between follicle cells and embryonic absorptive epithelia.

Keywords: fish viviparity, fetal nutrition, matrotrophy, lecithotrophy, placental analogs 


\section{INTRODUCTION}

Embryo development requires nutrients, and sufficient nutrient supply is the main factor for normal embryonic development. In oviparous species, embryos utilize the yolk in their eggs for development (Yu et al., 2014). However, in viviparous species, nutrition becomes more complex because embryos develop within the female body; thus, different sources of nutrients might be available from the pregnant female. The extant fishes that bear living young include chondrichthyans (sharks and rays) (40 families, 99 genera, and 420 species), Latimeria (1 family), and teleosts (13 families, 122 genera, 510 species) (Wourms, 1981). Different species have their own complex and specialized maternal-fetal related structures, which complicates the study of nutrient supply. Some species exhibit extreme lecithotrophy or extreme matrotrophy, but many other species exhibit with different degrees of matrotrophy. Consequently, there is a continuum of lecithotrophy and matrotrophy modes in viviparous species (Pollux et al., 2014; Blackburn, 2015). Nevertheless, there are only two sources of nutrients for viviparous fish: the embryonic yolk (lecithotrophy) and the pregnant female (matrotrophy).

Matrotrophic species provide substantial nutrients for their developing embryos via oophagy and adelphophagy, and placental analogs (Wourms, 1981; Blackburn and Vitt, 1992). Viviparous vertebrates have evolved maternal-fetal nutrient transfer structures. Although simple compared with those in mammals, in live-bearing fishes (in which fertilized eggs develop and hatch within the female ovary, called intraovarian gestation), these structures play an important role in studying nutritional systems. In teleosts, ovarian tissue has three effective modes of nutrient supply, the frequency trend in each mode is found as follows: absorption of ovarian histotrophs through (1) surface epithelia and a hypertrophied gut $>$ (2) trophotaeniae $>$ (3) the follicular pseudoplacenta (Wourms, 1981).

Some studies have been conducted on matrotrophic viviparous fishes in species of the family Sebastidae regarding the maternal-fetal relationship and matrotrophy over the past century. These studies were mainly performed from the viewpoints of histology, anatomy, physiology, and biochemistry, combined with light microscopy and electron microscopy. In 1984, the study of S. melanops found that (1) $81 \%$ of the initial yolk energy still remained at birth and $\sim 70 \%$ of the catabolic energy was supplied by the mother; and (2) there were no specialized processes for nutrient uptake, absorption by the embryo or assimilation of nutrients from the ovarian fluid (Boehlert and Yoklavich, 1984). In 1991, to find evidence of the absorption of maternal nutrients in S. schlegelii and $S$. melanops, researchers studied the ultrastructural features of the embryonic epidermis and rectum. During the later period of embryonic development, the embryonic epidermis absorbed low-molecular-weight substances, and after the development of the mouth, the hindgut absorbed large molecular substances (Shimizu et al., 1991). Additionally, $\left[{ }^{14} \mathrm{C}\right]$ phosphatidylcholine from S. flavidus maternal serum was detected in the embryos, and the radiolabeled content increased following embryo development. This was the first in vivo demonstration of maternal phospholipid nutrient supply in viviparous teleosts. This study suggested that nutrients are provided by the mother in the early to middle stages of embryonic development, since embryos maintained highly phosphorylated proteins and total protein content in the yolk, and nutrients stored in the yolk were used in the late stage of development (Macfarlane and Bowers, 1995). Another study used histological and immunohistological methods to demonstrate that nutrients were absorbed from ovarian fluid in the late stage of embryonic development in $S$. taczanowskii (Takemura et al., 1995).

In the past 5 years, studies on the functional and evolutionary morphology of viviparous fishes have been carried out in Poeciliidae (Torres-Martínez et al., 2017) and Goodeidae; these studies have helped us understand the mechanisms of embryo nutrition. Researchers found that early embryo development in Xenotoca eiseni (Goodeidae) was lecithotrophic based on embryonic morphology (Uribe et al., 2018). The embryo then transfers from the follicle to the ovarian cavity for further development, after which the nutritional mode for embryonic development of $X$. eiseni changes to matrotrophy. Schindler (2015) reviewed the structure and function of the placental exchange surface in goodeids and made a series of conclusions: during pregnancy, the inner ovary is hypervascularized and plays an important role as the maternal component of placental binding and nutrients are obtained from the inner epithelium of the ovary. Additionally, a comparative protein electrophoresis analysis of embryotroph and maternal blood serum indicated that the mother provides nutrients to embryos. The trophotaeniae, which are extensions of the embryonic caudal intestine to the ovarian lumen, provide a surface for embryo nutrient absorption. It is known that the $X$. eiseni trophotaeniae pseudoplacenta structure absorbs maternal nutrients before delivery and decreases nutrient supply after delivery; however, its removal mechanism needs to be further studied (Iida et al., 2015). This was the first report on the prenatal degeneration of a pseudoplacenta in a viviparous vertebrate and provided genetic support for the study of the genesis and degeneration of embryonic nutritional structures. Later researchers studied the tissue structure of the follicular pseudoplacenta in Heterandria formosa (Poeciliidae) using different staining methods and histological analysis (Guzman-Barcenas and Uribe, 2019). The ultrastructures of maternal follicular placentas of 11 species of poeciliids were identified by electron microscopy. Six ultrastructural characteristics (the number of vesicles, the area of vesicles, the number of microvilli, the length of microvilli, and the thicknesses of the follicle and follicle area) were described and the complexity of the structure was quantified. It was concluded that the existence of some placental structures improves the efficiency of nutrient transfer between the mother and embryo (Olivera-Tlahuel et al., 2018).

Sebastes schlegelii, known as the black rockfish, has a large head with obviously weak bone ridges and spines. The back is dark brown, with irregular dark black plaques, and the abdomen is gray white (Matsuda et al., 1984). The body length is generally $20-30 \mathrm{~cm}$ (Xi et al., 2017). The fish has a special viviparous reproductive system and is a commercially important mariculture fish in the Yellow Sea, the Bohai Sea, and the 
East China Sea. In this species, the gonads of males mature before those of females, the gonads of females mature after mating. Mating in male/female fishes occur in October of each year, then, females undergoing oocyte maturation complete fertilization using stored sperm in March of the following year. The pregnancy is completed when larvae are produced in the ovary. Since the 1990s, due to overfishing and environmental changes in fishing grounds, the availability of this species as a resource has significantly declined. It is increasingly urgent to protect germplasm resources, breed and release specimens, and optimize conditions for artificial breeding. In recent years, various studies have been conducted on S. schlegelii, including their aquaculture (Song et al., 2019; Zhang et al., 2019), ecology (Yin et al., 2018; Yu et al., 2019), reproduction, development, in vitro embryo culture, immunology (Du et al., 2019; Godahewa et al., 2019; Wang et al., 2019), sperm maturation induction, and sperm storage capacity (Liu et al., 2019); however, there is still little knowledge about the evolution of viviparity (He et al., 2019). Moreover, there are few reports on maternal nutritional supply in S. schlegelii, and the maternal-fetal relationship during gestation is unclear.

To gain insight into the nutrient supply Sebastes schlegelii at different stages of embryonic development, we selected fish during the pregnancy period as the main experimental subject and performed investigations using morphological, anatomical and histological methods. The structure of the ovary, especially the connection between the mother and fetus, was observed and described to indicate the mode of nutrient supply. The present study provides baseline knowledge for further research on the mechanism of embryonic nutrient supply and a theoretical basis for in vitro embryonic culture, artificial propagation, and germplasm resource protection.

\section{MATERIALS AND METHODS}

Eighteen female adult S. schlegelii were sampled from February to July 2019 from seawater culture cages in Weihai (Weihai, Shandong). Six reproduction stages or time points were considered in non-gestating, gestating, and postpartum fish: (1) phase III oocyte stage, (2) cleavage stage, (3) gastrula stage, (4) organ-forming stage, (5) 1 day after birth, and (6) 3 days after birth. Three females were selected in each of these reproduction stages (total $=18$ females). The specimens were sedated by adding the sedative MS-222 (Sigma-Aldrich, United States) to the water at a final concentration of $150 \mu \mathrm{g} / \mathrm{ml}$. After sedation, the abdominal cavity was opened by a lateral incision, and the ovary was quickly excised and fixed in $2.5 \%$ glutaraldehyde and Bouin's fixative. After fixation, the ovaries were dehydrated in a graded series of ethyl alcohol (30, 50, 70, and 95\%). The dehydrated ovaries were embedded in paraffin and sectioned at a thickness of $3-5 \mu \mathrm{m}$. The sections were stained with haematoxylin and eosin $(\mathrm{H} \& \mathrm{E})$. The samples that were fixed in $2.5 \%$ glutaraldehyde were observed by scanning electron microscopy (SEM). Anatomical analysis was directly observed under a stereoscope after dissection.

All experiments were performed in accordance with the relevant national and international guidelines and approved by the Institutional Animal Care and Use Committee, Institute of Oceanology, and Chinese Academy of Sciences.

\section{RESULTS}

\section{Anatomical Analysis (Light Microscopy)}

The light microscopy data highlight the predicted differences in the quantity of blood vessels and villi ovariales across different developmental stages. In this study, we collected two groups of samples for comparison and observed significant changes in the maternal-fetal connection structure during embryonic development. Microscopic observations of stage III ovarian samples showed sparse distributions of blood vessels around oocytes, the blood vessels present were underdeveloped, and very close to the oocytes (Figure 1). After fertilization, as the embryo developed, a large number of blood vessels, and villi ovariales proliferated in the ovary (Figure 2). Anatomically, a placenta-like fleshy red structure was isolated from the ovary (Figure 2A). A large number of primary blood vessels, secondary blood vessels and microvessels were observed under a stereoscope. The embryo was surrounded by villi ovariales and blood vessels (Figures 2B,C). It was further observed that the embryo was enclosed in an egg membrane, and a large number of capillaries (Figure 2D) were distributed along the egg membrane. During embryonic development, hyperplasia of
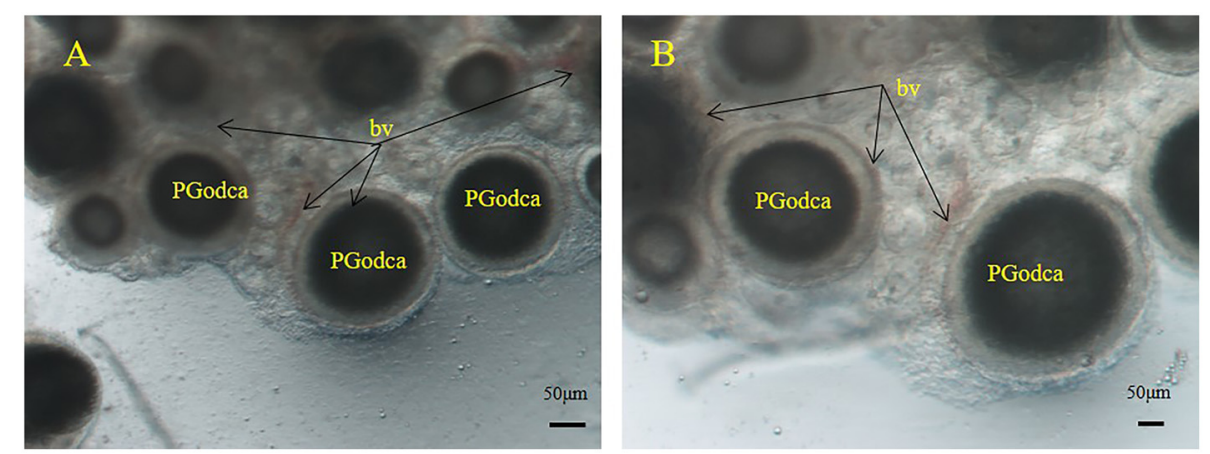

FIGURE 1 | S. schlegelii oocytes during the primary and secondary growth stages in ovaries. (A,B) Blood vessels (bv) surround oil droplet-cortical alveoli oocytes (PGodca). Scale bars, $50 \mu \mathrm{m}$ (A,B). 

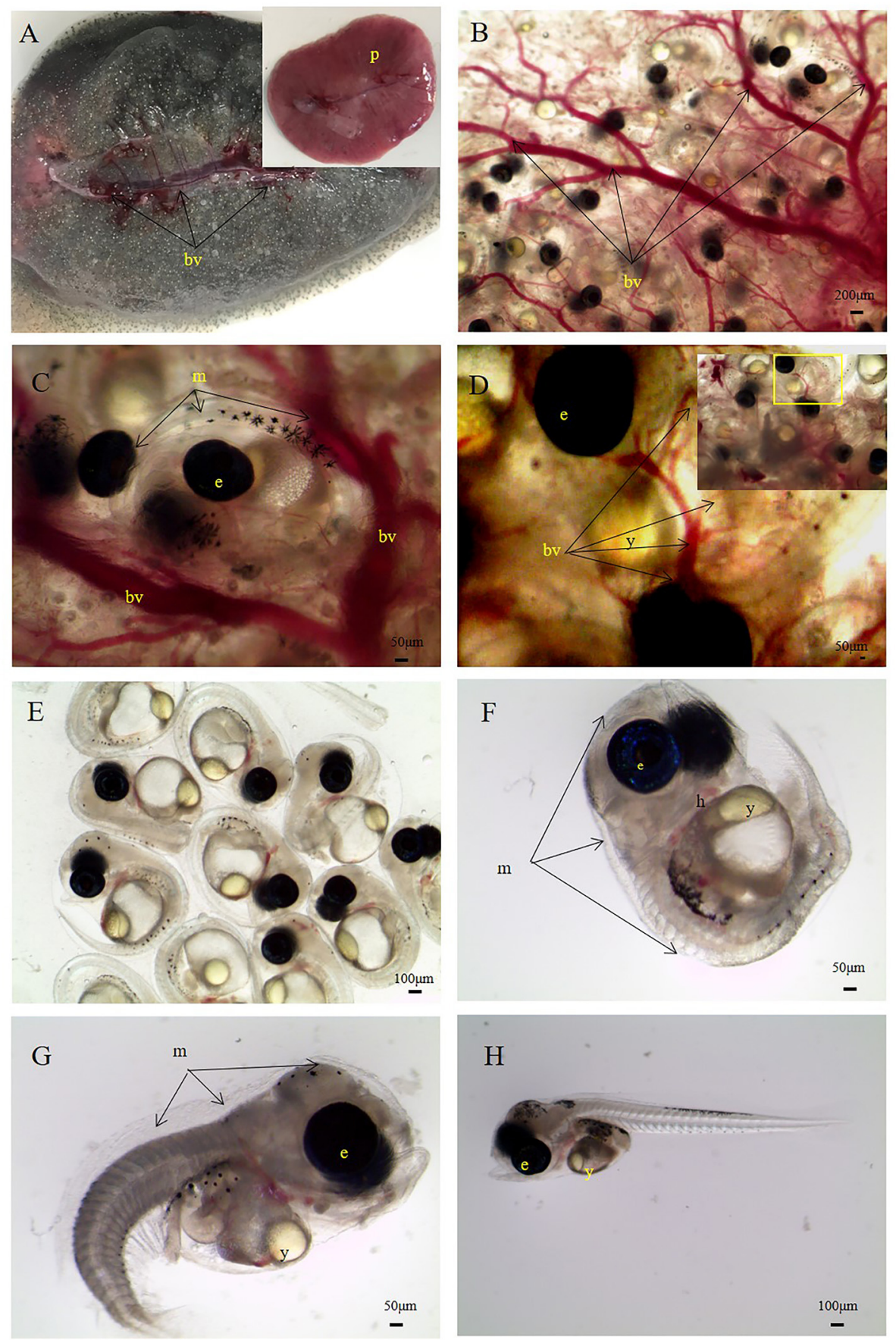

FIGURE 2 | S. schlegelii embryos during the organogenesis stage. (A) Ovary with a large central blood vessel (bv) and a placentome (p). (B) Embryos are surrounded by blood vessels. (C) An embryo wrapped in an egg membrane (m) with many blood vessels around. (D) Blood vessels around the egg membrane, (E) embryos, (F) an embryo enveloped by an egg membrane. (G) A newly broken and curled embryo. (H) A broken and unfolded embryo. e, eye of the embryo; h, heart of the embryo; y, yolk of embryo. Scale bars, $200 \mu \mathrm{m}$ (B); $50 \mu \mathrm{m}$ (C,D,F,G, ; $100 \mu \mathrm{m}$ (E,H).

villi ovariales, and blood vessels was observed. We speculated that the existence of these structures is closely related to the nutrient supply during the process of embryonic growth and development, and these closely connected structures are likely to be the structural basis of maternal nutrient transfer.
In this experiment, we selected ovaries in the organogenesis stage. Most of the embryos were enclosed in egg membranes, and yolk was present in the embryos (Figures 2E,F). We also found a few embryos in the ovary that lived outside of egg membranes (Figures 2G,H). 


\section{Scanning Electron Microscopy}

We collected embryos during organogenesis, selected three kinds of embryos, and described the surface and peripheral structures of embryos by SEM.

\section{Embryo Encasement in a sac Structure}

Encased embryos were surrounded by a thick sac structure (Figures 3, 4). The sac did not enclose the entire embryo tightly (Figures 3A, 4A); a part of the embryo was exposed. The exposed part comprised the egg membrane on the surface of the embryo. The egg membrane was a thin, non-cellular structure with many small holes (Figure 3D). In addition, we found that the embryo and sac were not closely connected, we could see a gap (Figures 3B,C, 4B,C). The sac was composed of multilayer connective tissue, follicular epithelial cells and blood vessels. In Figure 3, due to the relatively thick connective tissue covering, the follicular epithelial cells (Figures 4C,D) and blood vessels (Figure 4B) cannot be clearly distinguished. As shown in Figure 4, most of the connective tissue was fixed to form a branch shaped structure, which was collected at the top, and the lower part shows a layer of follicular epithelial cells and blood vessels located on the inner side near the embryo.

\section{Embryo Detachment From the Follicular Pseudoplacenta}

During development, embryos leave the maternal follicle and live in the liquid environment of the ovary (Figure 5). At this time, the embryo is enclosed by the egg membrane (Figure 5A).
Two states of the egg membrane, a smooth part and a folded part (ridge-like protuberance) can clearly be seen (Figures 5B,C). A swollen structure containing yolk droplets was observed (Figure 5D). The location of the yolk was noted and proved that yolk still existed in the embryo after separation from the follicle.

\section{Larvae}

During development, the embryo separates from the egg membrane and completes the hatching process. At this point, some structures still surrounding the larvae (Figures 6A,B). Figure 5 shows the structure of the swollen yolk droplet protuberance in the abdomens of larvae, proving that yolk still existed in larvae (Figures 6A,D). At this time, a large number of surface epithelial cells were present on the surfaces of the larvae (Figures 6B,C).

\section{Histology \\ Nongestation}

In the samples obtained in the middle of February, ovarian development was at stage III, and the ovary was light yellow in color. As the ovarian volume increased, the branches of the villi ovarialis increased, and the blood vessels developed, featuring large central vessels and branches. At this time, yolk granules can be observed through the ovarian membrane with the naked eye (Figure 7A). In the sections, we observed that the branches of the dendrites were villi ovarialis, which extended into the ovarian cavity. The oocytes were wrapped by the follicular membrane and hung-like grapes through the stalk of the follicle
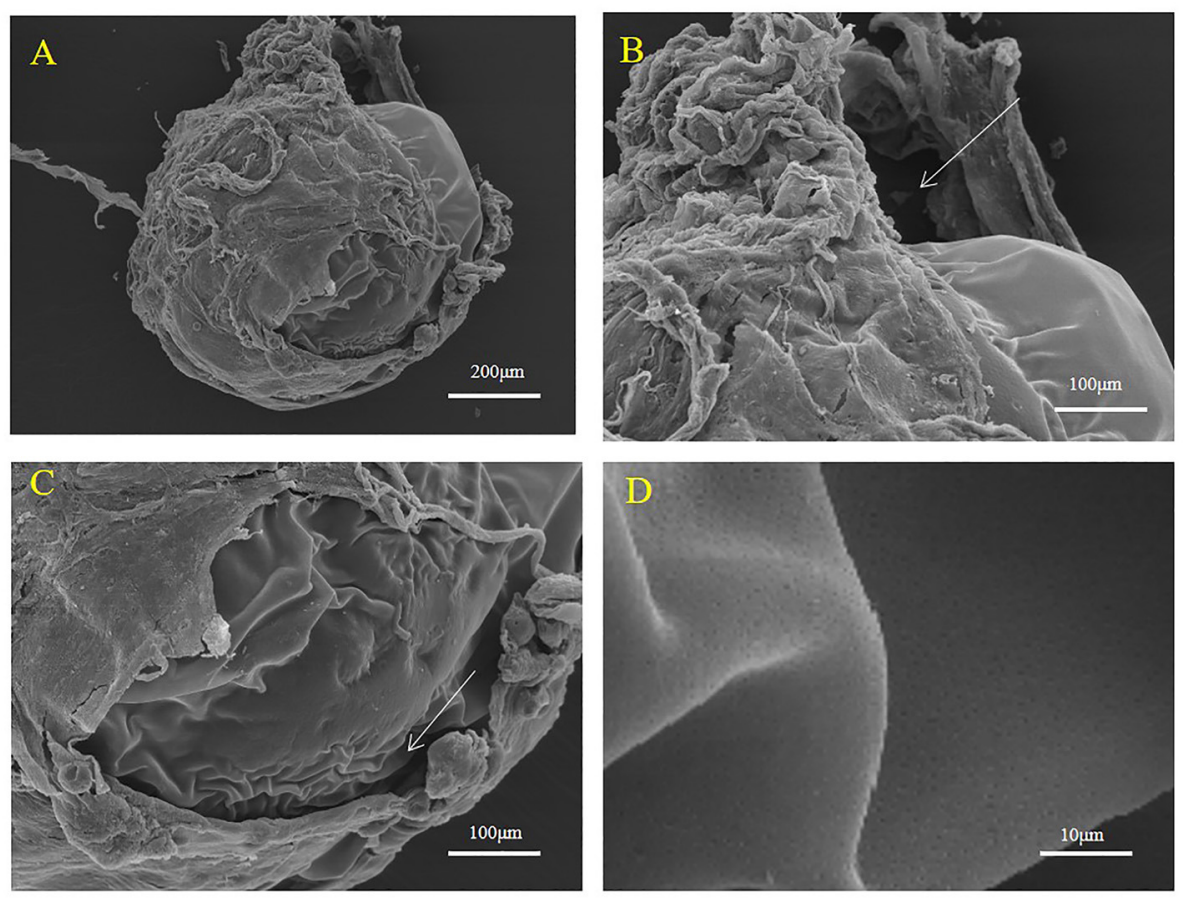

FIGURE 3 | Representative SEM images of the surface of the maternal follicle in S. schlegelii. (A) The embryo was wrapped in a follicle. (B,C) The embryo and the sac were not closely connected. (D) Many small holes existed on the surface of the thin egg membrane. The gaps were marked with arrows. Scale bars, $200 \mu \mathrm{m}$ (A); $100 \mu \mathrm{m}$ (B,C); $10 \mu \mathrm{m}$ (D). 

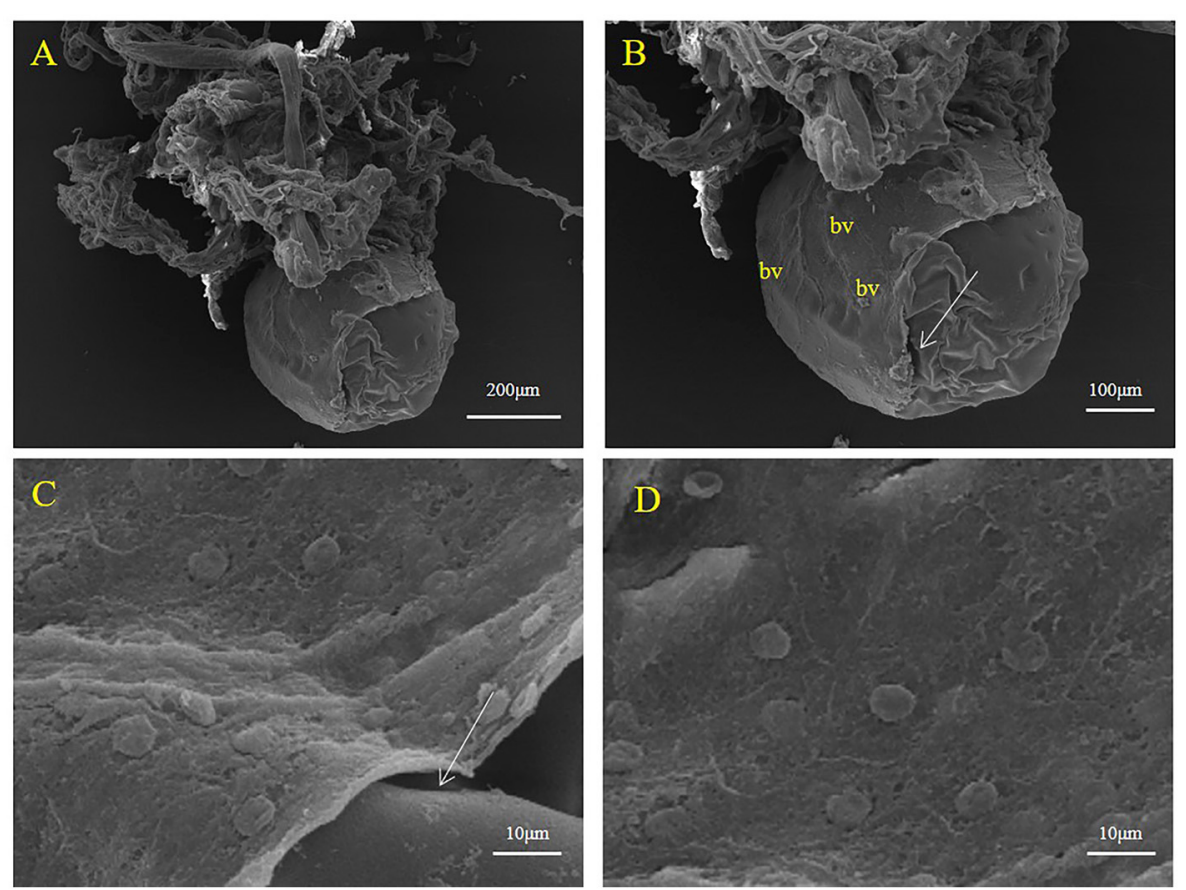

FIGURE 4 | Representative SEM images of the sac surface in S. schlegelii. (A) The embryo was suspended in branch structure. (B) Blood vessels (bv) and follicular epithelial cell layer. (C,D) Follicular epithelial cells. Gaps are marked with arrows. Scale bars, $200 \mu \mathrm{m}$ (A); $100 \mu \mathrm{m}$ (B); $10 \mu \mathrm{m}$ (C,D).
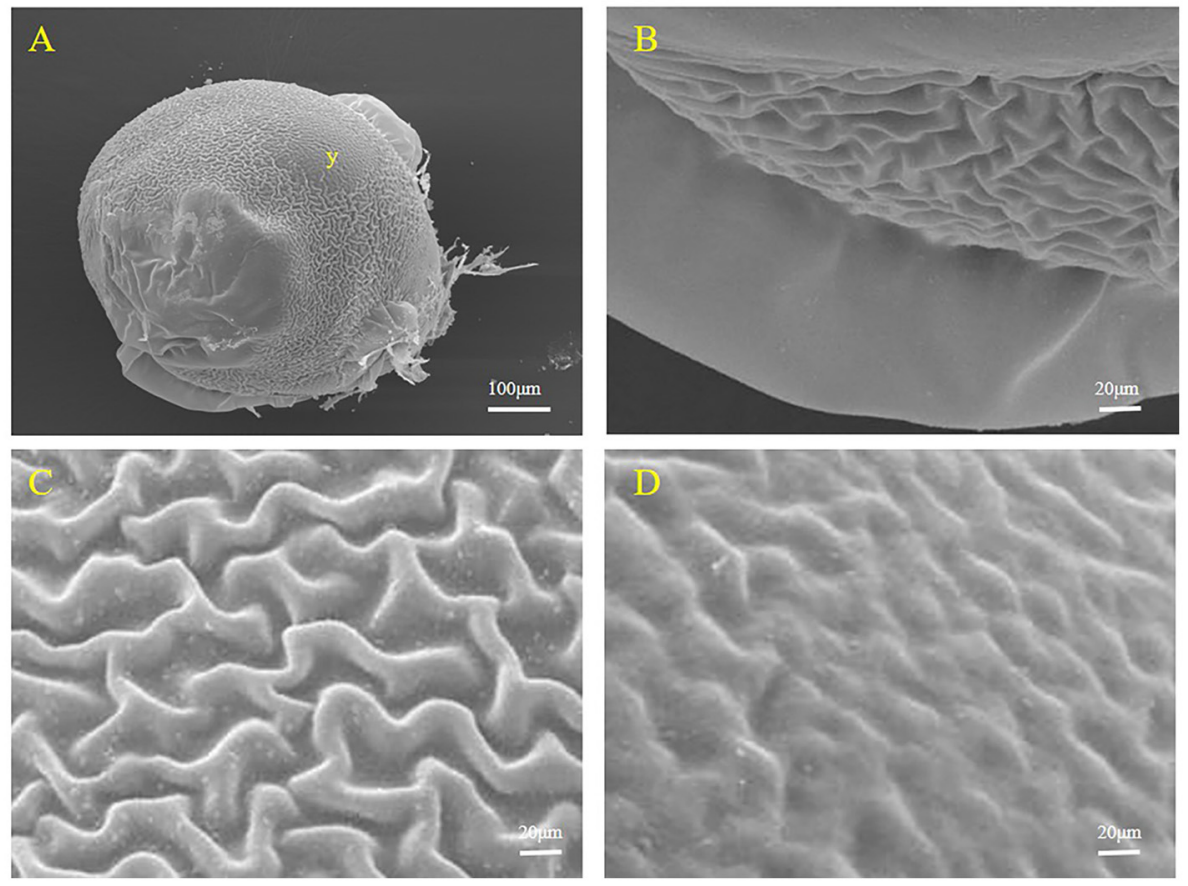

FIGURE 5 | Representative SEM images of the surface of an S. schlegelii embryo. (A) The whole surface of the embryo and the location of the yolk (y). (B) Smooth part of the egg membrane. (C) Folded part of the egg membrane. (D) Area bulging with yolk droplets. Scale bars, $100 \mu \mathrm{m}$ (A); $20 \mu \mathrm{m}$ (B-D).

(Figures 7B,C). Villi ovarialis were composed of follicles and the connective tissues. Folliole consisted of oocyte and many follicular cells (Figures 7D,E). The stage III ovary was mainly composed of phase III oocytes and early oocytes (Figures 7B-D). At this time, the oocytes are nearly round, the cytoplasm is weakly basophilic, and the oocytes begin to accumulate nutrients. There 

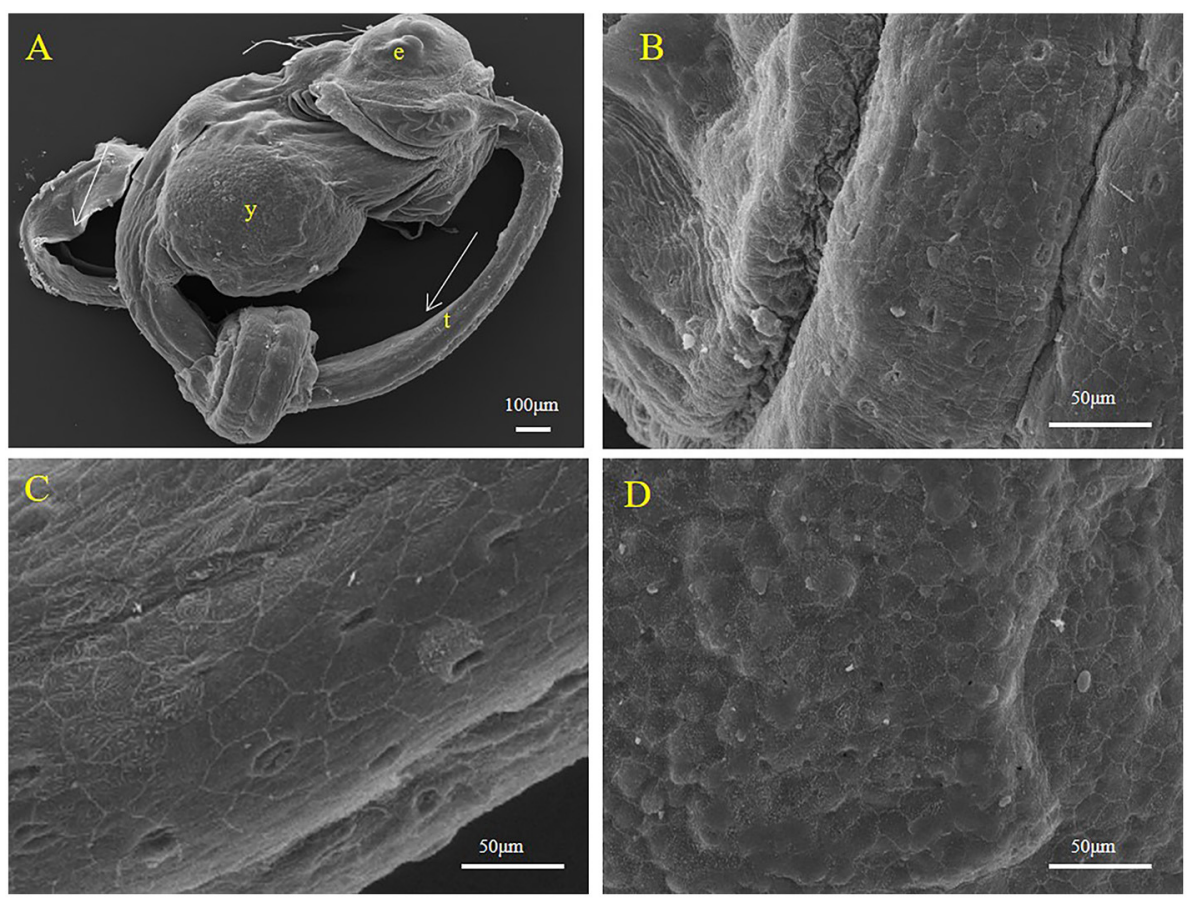

FIGURE 6 | Representative SEM images of the body surface of larval S. schlegelii. (A) The complete morphology of a larva. (B) The partialof a larva. (C) Surface epithelium of fish. (D) An area bulging with yolk droplets. Eyes (e), tail (t), and yolk (y) can be observed. Scale bars, $100 \mu \mathrm{m}$ (A); $50 \mu \mathrm{m}$ (B-D).

were small yolk granules in the cytoplasm near the inner edge of the plasma membrane and some small fat droplets around the nucleus of the oocyte. The cortical vesicles were sparse and not obvious. The nuclei were round to irregular, the large nucleoli disappeared, and dozens of small nucleoli appeared in the inner edge of the nuclear membrane (Figure 7E). At this time, the follicular membrane is composed of two layers: an inner layer (the granulosa layer), and an outer layer (the thecal layer). A zona pellucida existed between the egg membrane and the granulosa layer (Figures 7E,F). The blood vessels were highly branched, forming a capillary network distributed in the theca and wrapped around the follicles. The follicle stalk was to one side of the follicle and formed by the theca. The follicle hung from the branch structure.

\section{Gestation \\ Cleavage Stage}

In the early stage of embryo development, the volume of the ovary increased, the wall of the ovary thinned, the number of blood vessels increased, and the color of the ovary deepened from light yellow to bright orange yellow (Figure 8A). The embryo was enclosed by the egg membrane (Figure 8B); there were yolk and oil spheres in the egg envelope, and the embryo was situated the animal pole (Figure 8C). There was a layer of follicular epithelium around the embryo, around which epithelium there were blood vessels (Figure 8F). There was abundant connective tissue and blood vessels also surrounded immature or unfertilized eggs (Figures 8D,E).

\section{Gastrula Stage}

The volume of the ovary was further increased, the ovary was fleshy, and the ovarian fluid increased (Figure 9). It is speculated that the embryo absorbs nutrients from the ovarian fluid through the surface epithelium.

\section{Organ-Forming Stage}

The ovarian volume increased considerably as the embryo in the ovary developed and entered the late stage, close to delivery. At this time, the ovaries are black due to the eye and pigmentation (Figure 10A). The embryo was still enclosed in the egg membrane and surrounded by abundant loose connective tissue and blood vessels (Figures 10B-F). The yolk sac structure was located on the ventral side and contained yolk (Figures 10C-E).

\section{Postnatal Larva}

One day after delivery, there was still a small amount of yolk on the ventral surface (Figures 11A-D). However, with the growth and development of larvae in vitro, the yolk was consumed. Three days after delivery, no yolk was observed (Figures 11E-H).

\section{DISCUSSION}

Traditional classifications of fetal nutritional modes are lecithotrophy and matrotrophy, which represent two extremes of nutritional delivery modes. These modes are not limited to one reproductive pattern, they include both oviparity and viviparity; 

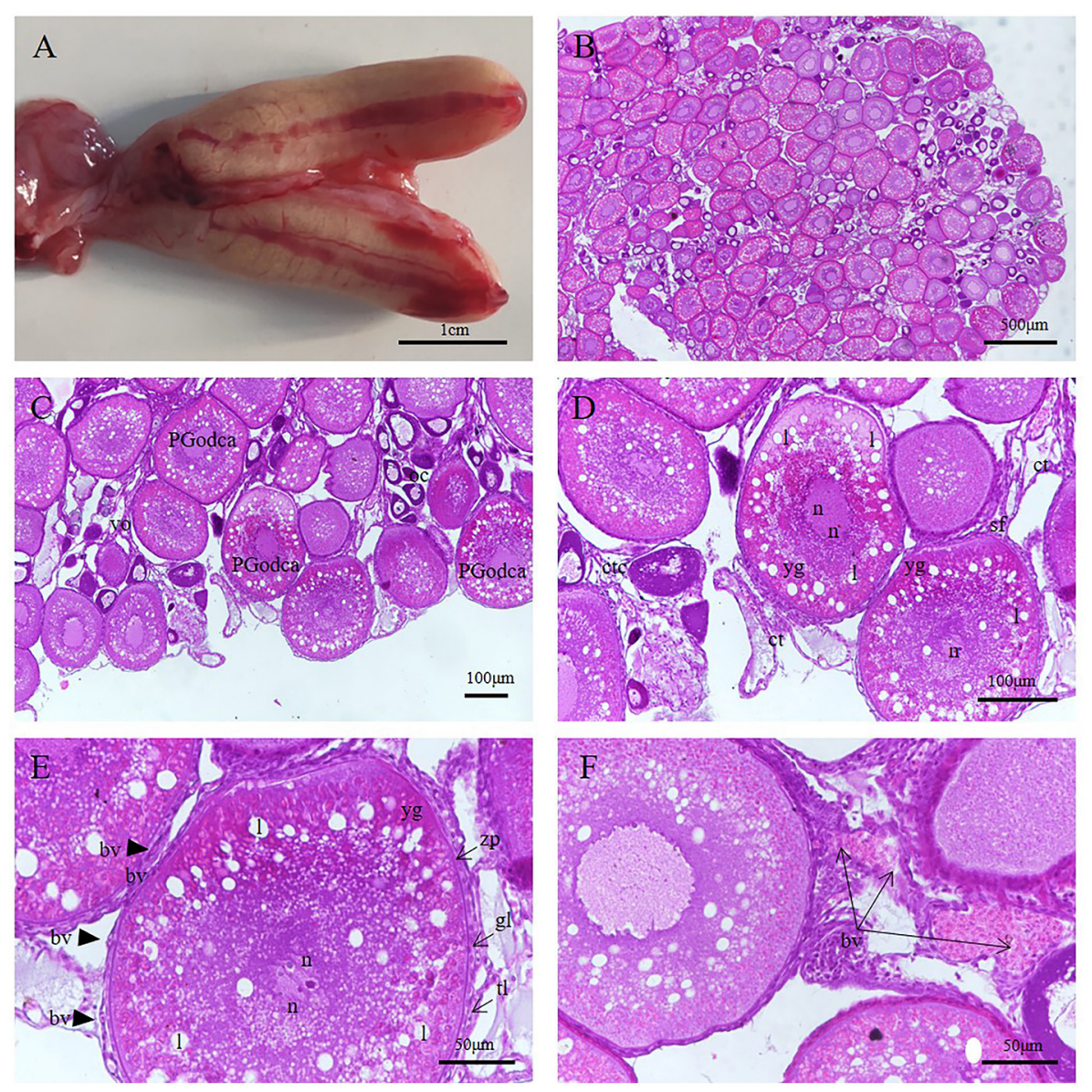

FIGURE 7 | S. schlegelii, oocytes during non-gestation. (A) Anatomical structure of the ovary. (B) The follicular cells hang on the villi ovarialis (vo) and form grape like structure. (C) The villi ovarialis (vo) were distributed along the ovarian cavity (oc), and the oocytes in different developmental stages were surrounded by follicular cells, mainly III phase oocytes, also called the primary and secondary growth stages oil droplet-cortical alveoli oocytes (PGodca). (D) Follicular cells hang on the villi ovarialis (vo) through the stalk of the follicle (sf). (E) III phase oocytes. There were small yolk granules (yg) were present in the cytoplasm near the inner edge of the plasma membrane and some small lipids (I) appeared around the nucleus (n) of the oocyte. The follicles are composed of oocytes and follicular cells. The follicular cells include a granulosa layer ( $\mathrm{gl}$ ) and thecal layer (tl), these are located outside the zona pellucida (zp), and there are blood vessels (bv) are present in the thecal layer(t). (F) Blood vessels (bv) and connective tissue (ct) of villi ovarialis (vo). Scale bars, $1 \mathrm{~cm}$ (A); $500 \mu \mathrm{m}$ (B); $100 \mu \mathrm{m}$ (C,D); $50 \mu \mathrm{m}$ (E,F). HandE stained.

therefore, it is better to classify them as two "sources" rather than as two modes. In many viviparous vertebrates, the embryos receive nutrients from these two sources (Wourms et al., 1988; Stewart, 1992; Thompson et al., 2000; Marsh-Matthews, 2011). Based on the bipartite system combined with the reproductive pattern (oviparity or viviparity), vertebrates have been classified as having four reproductive strategies: lecithotrophic oviparity, lecithotrophic viviparity, matrotrophic oviparity, and matrotrophic viviparity (or viviparous matrotrophy) (Blackburn, 2015). In lecithotrophic viviparous species, some incipient, limited, or minimal matrotrophic provision may also occur (Blackburn and Vitt, 1992; Blackburn, 2005a,b; Hamlett et al., 2005; Conrath and Musick, 2012). Matrotrophic viviparous species include various fishes, amphibians, and lizards. According to the traditional concept, $S$. schlegelii belongs to lecithophytic viviparity (Wourms, 1981). This study suggests that two kinds of nutritional modes occur in S. schlegelii: yolk nutrition and maternal nutrition. In contrast with limited or minimal nutrient provision, maternal nutrition exists in most stages of S. schlegelii embryonic development. The morphological evidence obtained by electron microscopy and anatomical and histological examinations shows that there is a structure for material transport between the mother and fetus during embryonic development.

In 1981, Wourms reported 10 forms of placental analogs (Wourms, 1981). In our research, we found that three forms of placental analogs may exist in S. schlegelii by comparing the morphological characteristics of the somatic cells around embryos and oocytes. These include external epithelial absorptive surfaces, trophonemata, with modifications to the epithelial tissue for absorbing histotroph and a follicular pseudoplacenta closely positioned between the follicle cells and embryonic absorptive epithelia. According to previous research, in the early stage of $S$. schlegelii development, many epithelial cells 

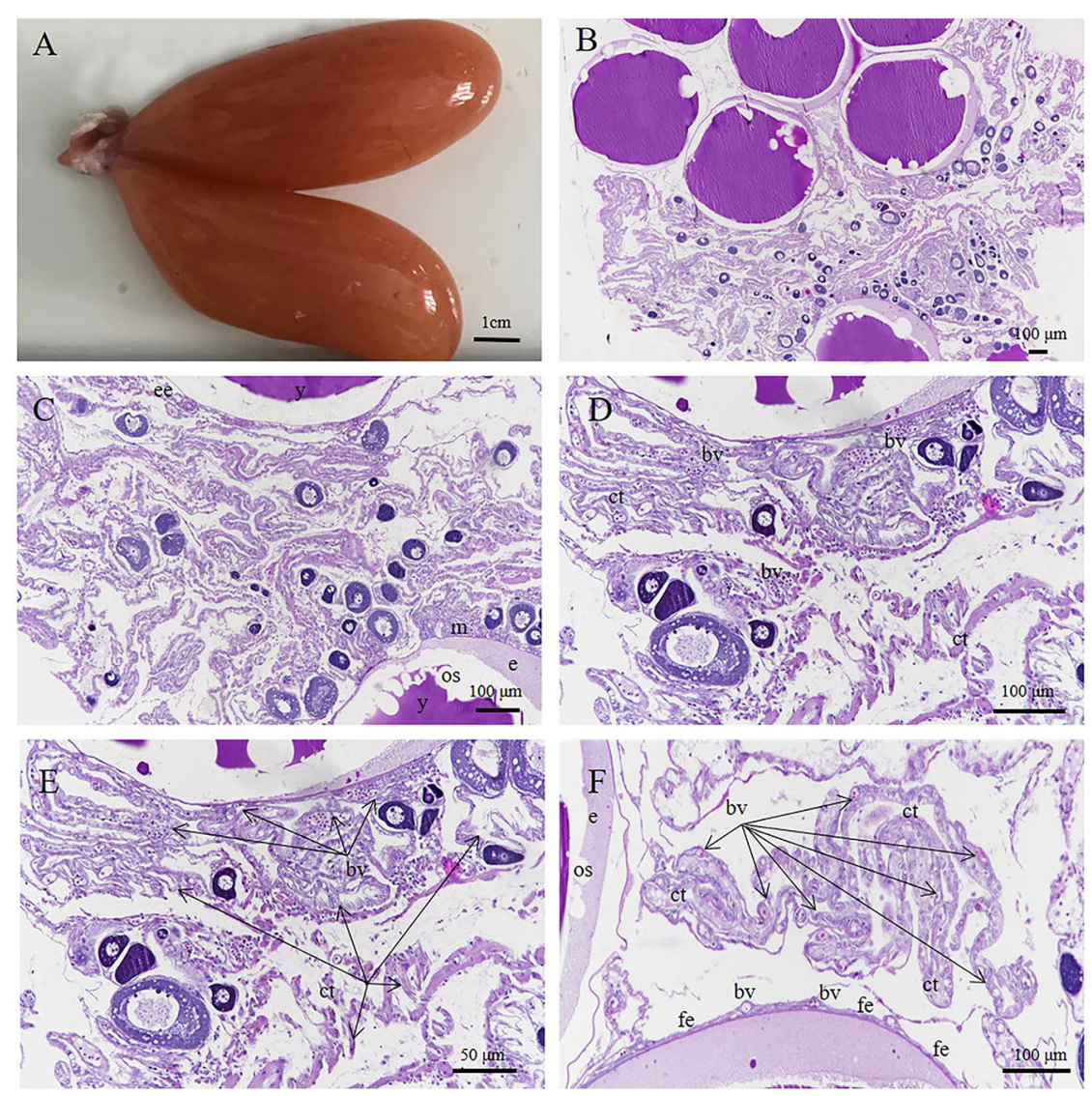

FIGURE 8 | S. schlegelii, embryos in the cleavage stage. (A) Morphology of ovary. (B) Embryos at cleavage. (C) The embryo (e) lives in the egg membrane (m), which contains yolk (y) and oil spheres (os). (D) Connective tissue (ct) and blood vessels (bv) surrounded immature or unfertilized eggs. (E) Connective tissue(ct) and blood vessels (bv) (F) A layer of follicular epithelium (fe) with many blood vessels (bv) around the embryo. Scale bars, $1 \mathrm{~cm}$ (A); $100 \mu \mathrm{m}$ (B-D,F); $50 \mu \mathrm{m}$ (E). HandE stained.
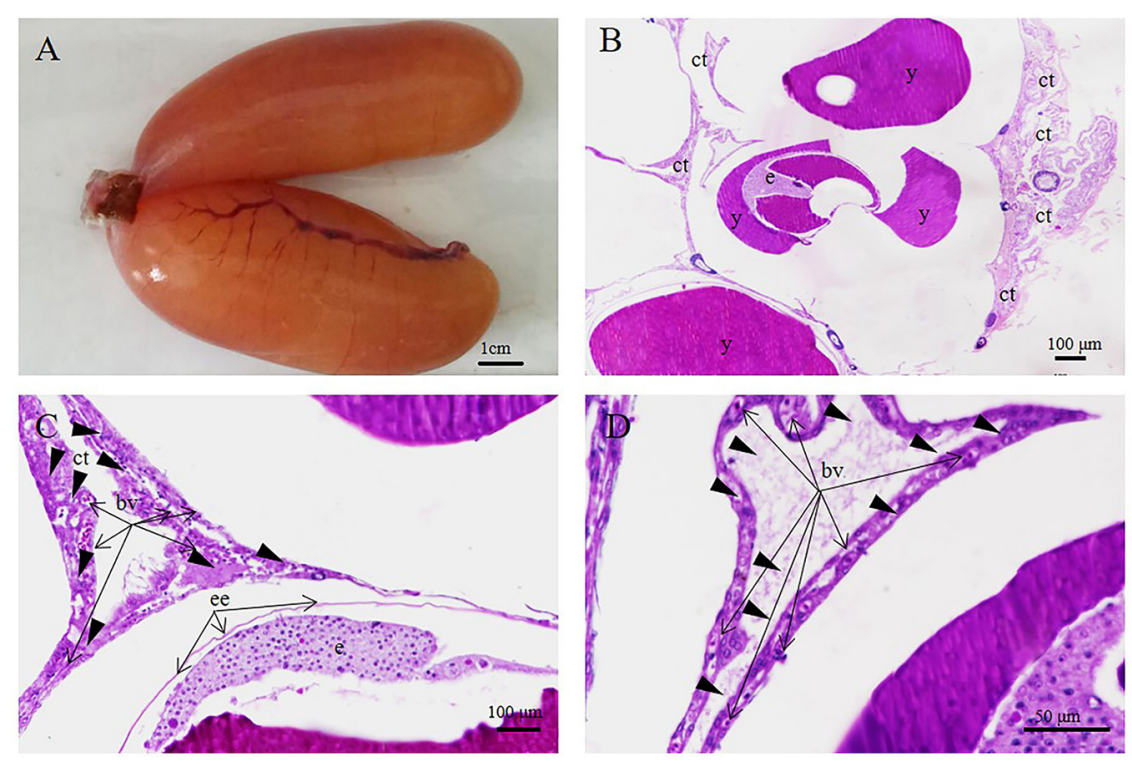

FIGURE 9 | S. schlegelii embryos in the cleavage stage. (A) Fleshy ovaries, (B) Loosely arranged embryo (e) with connective tissue (ct) attached. (C,D) Numerous blood vessels (bv) in the connective tissue (ct). Scale bars, $1 \mathrm{~cm}$ (A); $100 \mu \mathrm{m}$ (B,C); $50 \mu \mathrm{m}$ (D). HandE stained. 

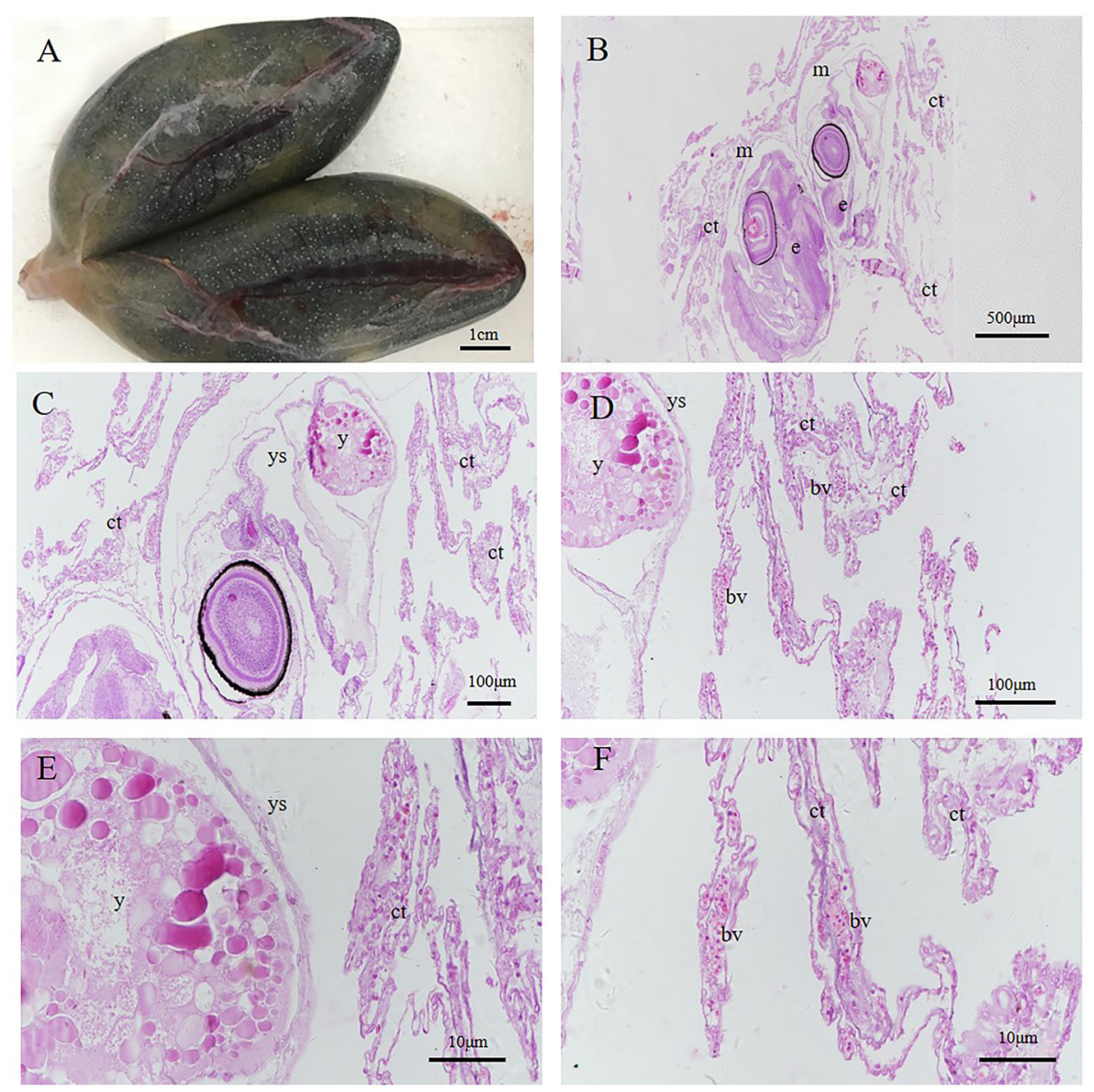

FIGURE 10 | S. schlegelii, embryos in the organ forming stage. (A) Black ovaries during organogenesis. (B) The embryo is located in the egg membrane (m) with loose connective tissue (ct) outside. (C) An embryo containing yolk. (D,E) Yolk in the yolk sac (ys). (F) Numerous blood vessels (bv) in the connective tissue (ct). Scale bars, $1 \mathrm{~cm}$ (A); $500 \mu \mathrm{m}$ (B); $100 \mu \mathrm{m}$ (C,D); $50 \mu \mathrm{m}$ (E,F). HandE stained.

differentiated from interstitial cells and combine with connective tissue and a large number of proliferating blood vessels to form a placental analog structure. Through this connection structure, the mother can continuously transfer large amounts of nutrients through the blood. The embryos absorb nutrients from the maternal blood for their own growth and development. At the later stages of embryo development, the connection of the embryo to the surrounding interstitial cells and connective tissue becomes loose. When we dissected the ovaries, we found that they contained large amounts of fluid. We speculate that the epithelium on the surface of the embryo directly absorbs the fluid to obtain nutrients to meet the needs of the developing embryo. In the final stage of embryo development and the primary stage of larval and juvenile development, the yolk nutrients are used. Some yolk exists until a few days after delivery.

The connection structure between the mother and fetus provides a structural basis for material transportation. Panhuis et al. (2017) examined the embryonic surface epidermis in the viviparous poeciliid genus Poeciliopsis and focused on embryo surface features that may facilitate maternal-fetal nutrient transfer. This research revealed common types of surface epithelial cells across species, including pavement cells with apical-surface microridges or microvilli and presumed ionocytes and mucus-secreting cells (Panhuis et al., 2017). Kwan et al. (2015) undertook a comprehensive comparative study of the maternal follicle in eight closely related Poeciliopsis species. Follicle sections and histology revealed that the epithelial folds of the extensive matrotrophs are comprised primarily of cuboidal and columnar cells and are richly supplied with capillaries (Kwan et al., 2015). Through the maternal-fetal junction structure, energy is not the only material source in the embryonic development of viviparous vertebrates. Yolk also plays an important role in the energy supply. However, there are few reports on how and when yolk can provide energy for viviparous fish. Some research has been carried out on reptiles. Powers and Blackburn (2017) studied the yolk-processing mechanisms in two colubrid snakes, the kingsnake Lampropeltis getula and the milksnake L. triangulum, using scanning electron microscopy and histology. They found that the close association between cells, yolk, and blood vessels allowed yolk material to be cellularized, digested, and transported for embryonic use (Powers and Blackburn, 2017). The embryo developmental process of 

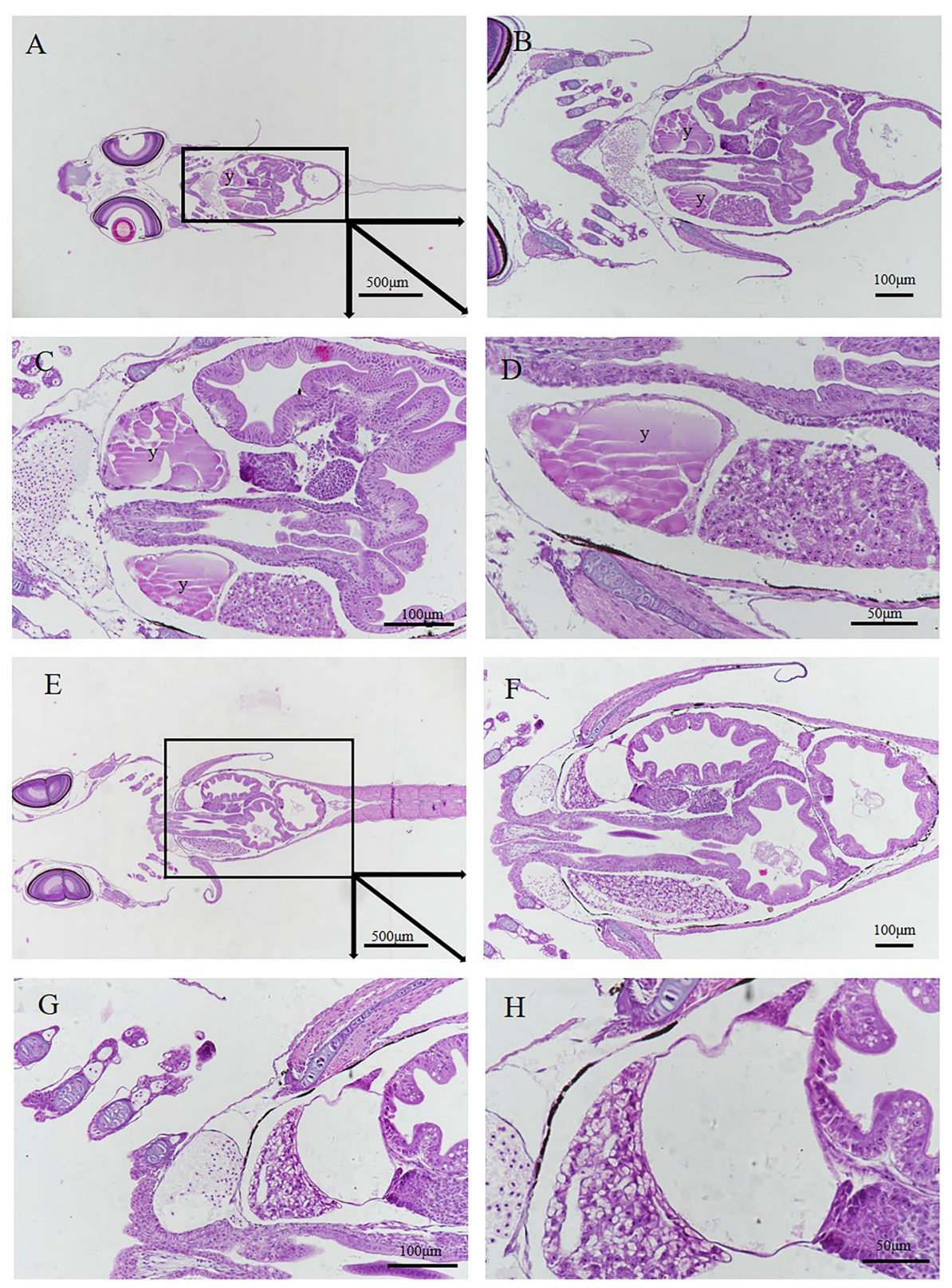

FIGURE 11 | Histology of postnatal larvae. (A-D) Larva 1 day after delivery with a small yolk (y) (E-H) 3rd day larva after delivery without yolk. Different parts were obtained by continuous sectioning. Scale bars, $500 \mu \mathrm{m}$ (A); $100 \mu \mathrm{m}$ (B,C,F,G); $50 \mu \mathrm{m}$ (D,H). HandE stained.

S. schlegelii features both maternal-fetal junction structures and yolk. How these fish supply nutrients and switch patterns will be the focus of the next stage of research.

\section{CONCLUSION}

According to anatomical evidence, placental-like structures are present during $S$. schlegelii embryonic development. Our results showed that after fertilization, the embryos live in an environment rich in blood vessels and connective tissue, and many capillaries appear adjacent to the egg membrane.
The SEM results showed that the embryo developed and was contained in a saclike structure composed of blood vessels, connective tissue, and surface epithelial cells. The histological results showed that villi ovarialis exist not only during the process of embryonic development but also at all levels of oocyte development. After fertilization, the embryo begins to develop, and the degree of vascularization in the villi ovarialis increases. Capillaries close to the embryo originally exist in the thecal layer, but as the embryo develops, the thecal cell layer and granular cell layer become less important, and the connection between the embryo and peripheral cells becomes 
increasingly loose. The cell layer most closely associated with the embryo is called the follicular layer, where the adjacent capillaries exist in the same positions as in the thecal cell layer. Starting from the gastrula stage, as various organs form, the connection between the embryo and surrounding cells becomes increasingly loose, and the ovarian fluid becomes increasingly abundant. We speculated that the nutrients needed for embryo development are released into the ovarian fluid through blood vessels and capillaries at all levels. The nutrients in the ovarian fluid are transported to the embryo through pores or related receptors on the surface of the embryo and are used for embryonic growth and development. In this study, we also observed small holes and cristae on the surfaces of embryos. According to the electron microscopy and histological findings, yolk was still available to $S$. schlegelii after rupture of the membrane and even after delivery, which indicates that the yolk provides nutrients for the fish development in the later stages of embryo development as well as in the early stage of larval and juvenile development. In conclusion, in $S$. schlegelii exhibits two types of nutritional modes in the process of embryo development: maternal nutrition (matrotrophy) and yolk nutrition (lecithothrophy).

\section{DATA AVAILABILITY STATEMENT}

The original contributions presented in the study are included in the article/supplementary material, further inquiries can be directed to the corresponding author/s.

\section{REFERENCES}

Blackburn, D. G. (2015). Evolution of vertebrate viviparity and specializations for fetal nutrition: a quantitative and qualitative analysis. J. Morphol. 276, 961-990. doi: 10.1002/jmor.20272

Blackburn, D. G. (2005a). “Evolutionary origins of viviparity in fishes," in Viviparity in Fishes, eds H. Grier, and M. C. Uribe (Homestead, FL: New Life Publications), 303-317.

Blackburn, D. G. (2005b). "Amniote perspectives on the evolution of viviparity," in Viviparity in Fishes, eds H. Grier and M. C. Uribe (Homestead, FL: New Life Publications), 319-340.

Blackburn, D. G., and Vitt, L. J. (1992). "Reproduction in viviparous South American lizards of the genus Mabuya," in Reproductive Biology of South American Vertebrates, ed W. C. Hamlett (NewYork, NY: Springer), 150-164. doi: 10.1007/978-1-4612-2866-0_11

Boehlert, G. W., and Yoklavich, M. M. (1984). Reproduction, embryonic energetics, and the maternal-fetal relationship in the viviparous genus Sebastes (Pisces: Scorpaenidae). Biol. Bull. 167, 354-370. doi: 10.2307/ 1541282

Conrath, C. L., and Musick, J. A. (2012). "Reproductive biology of elasmobranchs," in Biology of Sharks and Their Relatives, 2nd Edn, eds J. C. Carrier, J. A. Musick, and M. R. Heithaus (Boca Raton, FL: CRC Press), 291-311.

Du, X., Wang, G. H., Yue, B., Wang, J. J., Gu, Q. Q., Zhou, S., et al. (2019). A novel Clq domain containing protein in black rockfish (Sebastes schlegelii) serves as a pattern recognition receptor with immunoregulatory properties and possesses binding activity to heat aggregated IgG. Fish Shellfish Immunol. 87, 73-81. doi: 10.1016/j.fsi.2019.01.004

Godahewa, G. I., Perera, N. C. N., Kwon, H., and Lee, J. (2019). Cloning and functional characterization of rockfish peroxiredoxin 4 homolog

\section{ETHICS STATEMENT}

The animal study was reviewed and approved by the Institutional Animal Care and Use Committee, Institute of Oceanology, Chinese Academy of Sciences.

\section{AUTHOR CONTRIBUTIONS}

DT was responsible for the whole experiment design and operation, $\mathrm{XY}$ was responsible for providing the overall idea, $\mathrm{ZH}$ and $\mathrm{ZL}$ were responsible for some experiments, and others assisted in sampling. All authors contributed to the article and approved the submitted version.

\section{FUNDING}

This work was supported by National Key Research and Development Program (2018YFD0901204), Key Special Project for Introduced Talents Team of Southern Marine Science and Engineering Guangdong Laboratory (Guangzhou) (GML2019ZD0402), Major Agricultural Application Technology Innovation Project of Shandong Province (SD2019YY011), Qingdao National Laboratory for Marine Science and Technology (2018SDKJ0502-2), China Agriculture Research System (CARS-47), Major science and technology for scientific and technological innovation projects (Shandong) (2019JZZY020710), and STS Project (KFZD-SW-106, ZSSD-019, 2017T3017, and 2019T3022).

with its innate immune responses. Fish Shellfish Immunol. 88, 364-374. doi: 10.1016/j.fsi.2019.03.010

Guzman-Barcenas, M. G., and Uribe, M. C. (2019). Superfetation in the viviparous fish Heterandria formosa (Poeciliidae). J. Morphol. 280, 756-770. doi: 10.1002/jmor.20982

Hamlett, W. C., Kormanik, G., Storrie, M., Stevens, B., Walker, T. I. (2005). "Chondrichthyan parity, lecithotrophy and matrotrophy," in Reproductive Biology and Phylogeny of Chondrichthyes: Sharks, Batoids and Chimaeras, ed W. C. Hamlett (Enfield, NH: Science Publishers), 395-434.

He, Y., Chang, Y., Bao, L., Yu, M., Li, R., Niu, J., et al. (2019). A chromosome level genome of black rockfish, Sebastes schlegelii, provides insights into the evolution of live birth. Mol. Ecol. Resour. 19, 1309-1321. doi: 10.1111/1755-0998.13034

Iida, A., Nishimaki, T., and Sehara-Fujisawa, A. (2015). Prenatal regression of the trophotaenial placenta in a viviparous fish, Xenotoca eiseni. Sci. Rep. 5:7855. doi: $10.1038 /$ srep07855

Kwan, L., Fris, M., Rodd, F. H., Rowe, L., Tuhela, L., and Panhuis, T. M. (2015). An examination of the variation in maternal placentae across the genus Poeciliopsis (Poeciliidae). J. Morphol. 276, 707-720. doi: 10.1002/jmor.2 0381

Liu, Q., Wang, X., Xiao, Y., Zhao, H., Xu, S., Wang, Y., et al. (2019). Sequencing of the black rockfish chromosomal genome provides insight into sperm storage in the female ovary. DNA Res. 26, 453-464. doi: 10.1093/dnares/dsz023

Macfarlane, R., and Bowers, M. (1995). Matrotrophic viviparity in the yellowtail rockfish Sebastes flavidus. J. Exp. Biol. 198, 1197-1206.

Marsh-Matthews, E. (2011). "Ecology and evolution of poeciliid fishes," in Matrotrophy, eds J. Evans, A. Pilastro, O. Schlupp (Chicago: University Chicago Press), 18-27.

Matsuda, H., Amaoka, K., Araga, C., Uyeno, T., and Yoshino, T. (1984). The Fishes of the Japanese Archipelago. Tokyo: Tokai University Press. 
Olivera-Tlahuel, C., Moreno-Mendoza, N. A., and Villagrán-Santa, C. M. (2018). Placental structures and their association with matrotrophy and superfetation in poeciliid fishes. Acta Zool. 100, 167-181. doi: 10.1007/10.1111/azo.12244

Panhuis, T. M., Fris, M., Tuhela, L., and Kwan, L. (2017). An examination of surface epithelium structures of the embryo across the genus Poeciliopsis (Poeciliidae). J. Morphol. 278, 1726-1738. doi: 10.1002/jmor.20745

Pollux, B. J., Meredith, R. W., Springer, M. S., Garland, T., and Reznick, D. N. (2014). The evolution of the placenta drives a shift in sexual selection in livebearing fish. Nature 513, 233-236. doi: 10.1038/nature13451

Powers, K. G., and Blackburn, D. G. (2017). A novel pattern of yolk processing in developing snake eggs (Colubridae: Lampropeltini) and its functional and evolutionary implications. J. Exp. Zool. B Mol. Dev. Evol. 328, 462-475. doi: $10.1002 /$ jez.b.22750

Schindler, J. F. (2015). Structure and function of placental exchange surfaces in goodeid fishes (Teleostei: Atheriniformes). J. Morphol. 276, 991-1003. doi: 10.1002/jmor.20292

Shimizu, M., Kusakari, M., Yoklavich, M. M., Boehlert, G. W., and Yamada, J. (1991). Ultrastructure of the epidermis and digestive tract in Sebastes embryos, with special reference to the uptake of exogenous nutrients. Environ. Biol. Fish. 30, 155-163. doi: 10.1007/978-94-011-3792-8_16

Song, M., Zhao, J., Wen, H. S., Li, Y., Li, J. F., Li, L. M., et al. (2019). The impact of acute thermal stress on the metabolome of the black rockfish (Sebastes schlegelii). PLoS One 14:e0217133. doi: 10.1371/journal.pone.0217133

Stewart, J. R. (1992). Placental structure and nutritional provision to embryos in predominantly lecithotrophic viviparous reptiles. Am. Zool. 32, 303-312. doi: $10.1007 / 10.1093 / \mathrm{icb} / 32.2 .303$

Takemura, A., Takano, K., and Takahashi, H. (1995). The uptake of macromolecular materials in the hindgut of viviparous rockfish embryos. J. Fish Biol. 46, 485-493. doi: 10.1111/j.1095-8649.1995.tb05989.x

Thompson, M. B., Stewart, J. R., and Speake, B. K. (2000). Comparison of nutrient transport across the placenta of lizards differing in placental complexity. Compar. Biochem. Physiol. A. 127, 469-479. doi: 10.1016/s1095-6433(00)00277-4

Torres-Martínez, A., Hernández-Franyutti, A., Uribe, M. C., and ContrerasSánchez, W. M. (2017). Ovarian structure and oogenesis of the extremophile viviparous teleost Poecilia mexicana (Poeciliidae) from an active sulfur spring cave in Southern Mexico. J. Morphol. 278, 1667-1681. doi: 10.1002/jmor.20740

Uribe, M. C., Grier, H. J., Avila-Zúñiga, S. A., and García-Alarcón, A. (2018). Change of lecithotrophic to matrotrophic nutrition during gestation in the viviparous teleost Xenotoca eiseni (Goodeidae). J. Morphol. 279, 1336-1345. doi: $10.1002 /$ jmor.20874
Wang, G. H., Wang, J. J., Yue, B., Du, X., Du, H. H., Zhang, M., et al. (2019). High mobility group box 2 of black rockfish Sebastes schlegelii: Gene cloning, immunoregulatory properties and antibacterial effect. Fish Shellfish Immunol. 84, 719-725. doi: 10.1016/j.fsi.2018.10.066

Wourms, J. P. (1981). Viviparity: the maternal-fetal relationship in fishes. Am. Zool. 21, 473-515. doi: 10.1093/icb/21.2.473

Wourms, J. P., Grove, B. D., and Lombardi, J. (1988). "The maternal embryonic relationship in viviparous fishes," in Fish Physiology Vol. XI: The Physiology of Developing Fish. B. Viviparity and Posthatching Juveniles, eds W. S. Hoar, and D. J. Randall (San Diego, CA: Academic Press), 2-134.

Xi, D., Zhang, X. M., Lü, H. J., and Zhang, Z. (2017). Prediction of cannibalism in juvenile black rockfish, (Sebastes schlegelii) (Hilgendorf, 1880), based on morphometric characteristics and paired trials. Aquac. Res. 48, 3198-3206. doi: 10.1111/are.13150

Yin, L., Chen, B., Xia, B., Shi, X., and Qu, K. (2018). Polystyrene microplastics alter the behavior, energy reserve and nutritional composition of marine jacopever (Sebastes schleglii). J. Hazard. Mater. 360, 97-105. doi: 10.1016/j.jhazmat.2018.07.110

Yu, D. D., Liu, M., Liu, H. J., et al. (2014). The embryonic development of Gadus macrocephalus Tilesius. Marine Sci. 38, 80-86.

Yu, Y., Zhang, Z., Wang, Y., Liao, M., Rong, X., Li, B., et al. (2019). Complete genome sequence of Photobacterium damselae Subsp. damselae strain SSPD1601 isolated from deep-sea cage-cultured Sebastes schlegelii with septic skin ulcer. Int. J. Genomics. 2019, 1-7. doi: 10.1155/2019/4242653

Zhang, Z., Yu, Y. X., Jiang, Y., Wang, Y. G., Liao, M. J., Rong, X. J., et al. (2019). First report of isolation and complete genome of Vibrio rotiferianus strain SSVR1601 from cage cultured black rockfish (Sebastes schlegelii)associated with skin ulcer. J. Fish Dis. 42, 623-630. doi: 10.1111/jfd.12963

Conflict of Interest: The authors declare that the research was conducted in the absence of any commercial or financial relationships that could be construed as a potential conflict of interest.

Copyright (c) 2021 Tengfei, Yongshuang, Haixia, Li, Qinghua, Xueying, Jun, Shihong, Yanfeng, Jiachen, Lele, Yunong and Guang. This is an open-access article distributed under the terms of the Creative Commons Attribution License (CC BY). The use, distribution or reproduction in other forums is permitted, provided the original author(s) and the copyright owner(s) are credited and that the original publication in this journal is cited, in accordance with accepted academic practice. No use, distribution or reproduction is permitted which does not comply with these terms. 